\title{
Representation and Control in Vision
}

\author{
Takeo Kanade
}

\author{
Department of Computer Science \\ Carncgic-Mcllon University \\ Pittsburgh, Pa. 15213
}

\section{Introduction}

One of the central issues in vision is how to represent and use knowledge relevant to understanding the imagc. Partly becausc vision is so difficult. and partly becausc even the cheapest solutions can still be so uscfu\}. npproaches to vision problems have had a tendency to be ad hoc and heuristic. Recently, however. new thrusts in computer vision are emerging. most notably in the Image Understanding community, that try to pursue morc systcmatic and computational approaches. [1]

This article attempts to introduce such new Image Understanding approaches to vision. It first presents the author's view of structure of vision: what types of information must be dealt with and what lcvels of knowlcdgc are involved in transforming one type of information into another. Then, representative research progress in Image Understanding is reviewed which addresses use and representation of knowledgc in vision. Specifically. wc will discuss:

e Formalization of physical knowledge into computational forms

e Use of 3D models

e Construction of scciic descriptions from images

e Organization and control of vision systems

\section{Structure of Vision}

let us consider what vision really is. Vision involves visual sensing and interpretation. Visual sensing is a projection of a physical cnvironment into a form of representation called images Projection can vary from the most ordinary picturc taken by cameras to active sensing such as by laser range finders. Images can alsu range from a single-point light flux meitsurement to 3-dirnensional range data. Then vision is defined as a precess of understanding the cnvironment througli the projected images, or in short inverse projection.

l'he vision prekess must involve various types of information. Figure 1 is a schematic diagram showing one possihle dichotomy of such types and their primary relationships. [14] 'l'he general idea is as follows: given an image clics (picture domain cues or secme domain cues) are cxtracted: these are then used to alceess the medefof the task world and to instantiate it: the instamiated model is verificd by projecting it bick to the picture level (piefure imlerpretation) and by matching it with the input imagc. 'l'his positive feedback loop is the basic drive in the analysis prexess.

Scvcral points should be noted about this mtdcl. First of all, therc is an important distinction hetwecn the picturc domain and the secne domain. In short. a picture is a projection of a scene. Thus the picture domain cues are the featurcs observed in the picturc. such as line segments. homogencous regerns, intensity gradicnts. ctc. 'l'he secne domain cues are the features which are the cause of the picture domain cues. such as cdge configurations, surface oricntations, reflectances, volumes ctc. 'l'his distinction preveiits oiic froun confusing features in the picture domain with those in the sene dornain. For example, the "above" or "idjacent" lidiconship hetween regions in the picture does not necessarily correspond to the "on" or "next-to" relation betwecn objects. Though the most basic and important Scene domain cues are spatial three-dimensional (3-D) configurations, therc arc other important ones, such as reflectances and lighting conditions. The model contains the generic descriptions of the task world. It can be thought of as containing information about the gencric shapcs of objects and rclations among them. Notc that gencnc

NATO ASI Series. Vol FA

Pictorial Data Analysis. Fdited by K M.Hiaralick

C. Springer-Verlag Berlin IJeidelberg 1983 


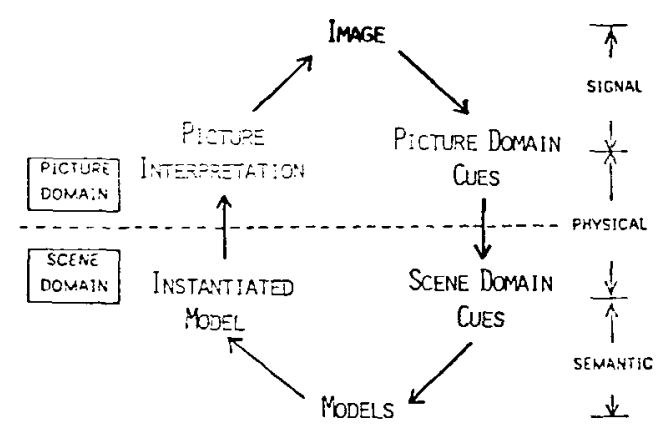

Figure I: A model of vision process. Roughly speaking, the right half of the cycle corresponds to the data-driven. bottom-up. hypothesis-generation phase, and the left half to the model-driven. topdown. verification phasc of vision.

models are to be represented in terms of scenc domain cues. The instantiated model is the specific situation being depicted in the picturc: the specific objects. their sizes, their placement, etc. The picturc interpretation is a projection (an anticipated picturc) of the instantiated model under the specific conditions (view direction. lighting conditions, ctc.). It gives an explanation of the imagc by the descriptions such as what lincs and regions of what propcrtics should apnear in the image. what set of lincs or regions constitute the objects. and so on. $A$ n example of this typc of information is an image segmented into regions with scmantic labels attached to cach. It is different from an mmage which is only a collection of image fcaturcs. such as color and intensity.

The model of Figure 1 involves threc levels of knoxlcdge -- signal. physical. and semantic. Roughly speaking. the signal level involves manipulating image features as 2-D patterns, the physical level involves bridging the picturc and scenc domains so that umage features can be interpreted as scene features, and the semantic level involves working in the scenc domain to exploit the task world constraints.

The difference among these levels can be illustrated by the following cxamplc. Suppose that a histogram of the gray levels of an imagc shows a clear bimodality. The value at the valley is often sclectcd as a good threshold. This is based on the signal level knowledge that in such a casc often two sources of monomodal distribution are prescnt. Thereforc. a threshold value at that valley will give a good splitting of the image. We are also assuming that a salt-and-pcppcr imagc (which can produce the same histogram) is rare. This signal-level histograming tcchniquc is actually based on physical level knowlcdge. We know that two surfaces, whose reflectivity characteristics arc diffcrent from each other but constant within cach. or which have different oricntations. can produce two regions in the image whose fray levels arc different but relatively constant within each. Why is it significant to extract those surfaccs for understunding the irnagc? Because we knou that surfaces with different reflectance or oricntations arc the semantically meaningful units which constutute the objects in our world.

As another example. the extraction of straight lincs by detecting sudden changes of intensity on the signal level is justificd by the physical-level observation that such intensity changes arc caused by sudden change of oricntations (convexity and concavity). distance (occlusion). illumination (shadow). and reflectance (matcrial change), all of which arc usually importnnt clues in the scmantic analysis of the scene content.

It is not meant that the analysis should always follow the routes shown in Figurc 1. In fact. one can combine seseral steps into onc. or precompile necessnry knowledgc ahout some entitics into a processing pricedure, so that those crutucs are not explicitly treated. Howerer. the meaning and limitations of many methods can he illustrated by considcring what types of knowledge are incorporated into them. according to this paradigm.

Notice that essential difficulties in vision iirc in crossing the houndary hetween the seene and picture domains from picture to scciic: it is ambiguous thus additional constraints are to be used. Generality of wson depends on how (1) derive and use necessary constrants. 


\section{Converting Physical Level of Knowledge into Computational Constraints}

Historically, there are several annoying image phenomena which often cause vision programs to fail in image analysis: they include deformed shape due to slanted views, shadings due to curved surfaces and lighting, and textural patterns. and shadow. That may be still true in most applications, but it has begun to be understood that these are rich sources of information about object shape. An interesting class of theories have been developed to handle these sourccs. They arc all for relating picture domain cues with scene domain cues so that they can be used in recovering 3-dimensional scene features from images. This section will briefly introduce such theories which allow computational usage of constraints from image intensity and geometry in order to exploit 2D-shape, shading, texture. and shadow in the image.

Sincc wc will use gradient space [32][20] throughout the section as a convenient tool to represent surface oncntations. let us first definc it. Our coordinate system $x-y-z$ is placed so that the optical axis is the $z$ axis and the image plane is the $x \cdot y$ plane. (Sce Figure 2.) Consider a surface,

$$
-y=f(x, y)
$$

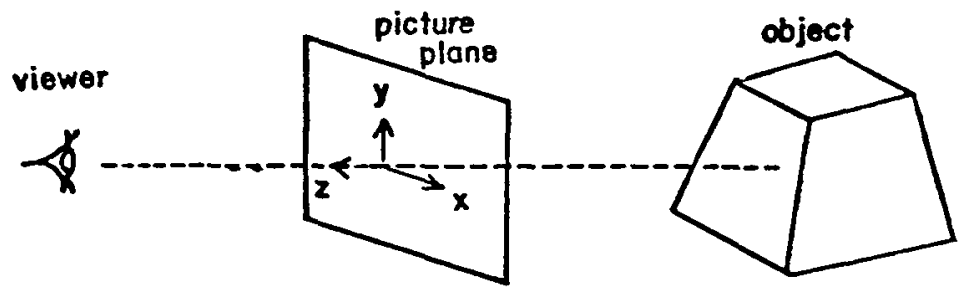

planes: $-z=p x+q y+c \rightarrow$ point: $(p, q)$

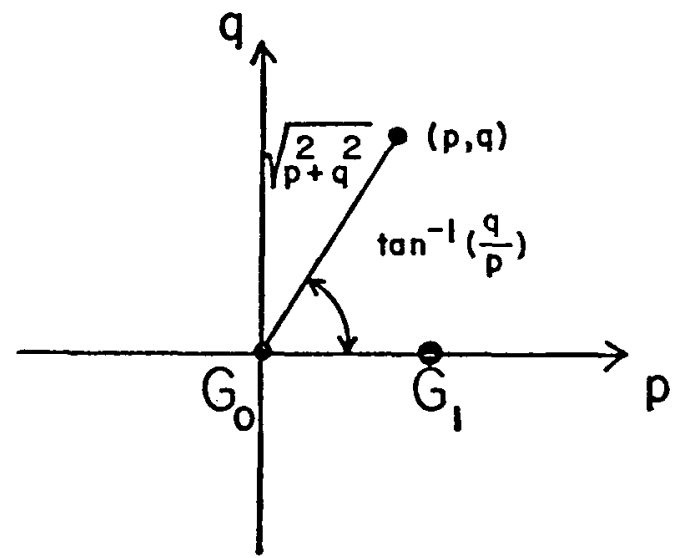

(b)

Figure 2: (a) lmaging geometry including the object. the picture, and the viewer. (b) mapping of planes to a gridient. 
The gradient space is defined by $(p, q)$ where

$$
p=\frac{\partial f}{\partial x}, q=\frac{\partial f}{\partial y}
$$

That is, $p$ and $\mathbf{q}$ arc the rate of change in depth on the surface along the $\mathbf{x}$ and $\mathbf{y}$ direction. We can casily see that $(p, q, 1)$ has the direction of the surface normal.

Gradients arc constant over a planar surface, and the gradient $(p, q)$ corresponds to a set of parallel plancs:

$$
-z=p x+q y+c
$$

where $\mathrm{c}$ is arbitrary. Throughout this section we will assume orthographic projection for simplicity rather than perspcctive projection.

Under orthographic projection. the gradients of plancs and the image line on the image have an intercsting rclationship. Referring to Figure 3, let two plancs $P_{1}$ and $P_{2}$ intersect in the space and let the intersection cdge be depicted as a line $/$ in the image. Then the linc in the gradient space connecting the corrcsponding gradicnts $G_{j}=\left(p_{j}, q_{i}\right)$ is perpendicular to the linc $l$. This can bec seen in the following way. The normals of the two surfaces have dircetions $n_{1}=\left(p_{1}, q_{1}, 1\right)$ and $n=\left(p_{2}, q_{2}, 1\right)$. Their cross product $n_{1} \times n_{2}$, represents the dircetion of the intersection cdgc in the space. Since we assume orthographic projection the dircetion of the line $l$ in the image is given by the $x$ and $y$ components of this cross product: 1.c.. $\left(q_{1}-q_{2}, p_{2}-p_{1}\right)$. This vector is obviously perpendicular to the vector $G_{1}-G_{2}=\left(p_{1}-p_{2}\right.$. $q_{1}-q_{2}$ ) which connects $G_{1}$ and $G$,. Morcover if the intersection cdge is convex vicwed from the vicwer, then the positional order of $G_{1}$ and $G_{2}$ is the same as the regions in the picture corresponding to $P_{1}$ and $P$,: if concavc. the order is reversed.
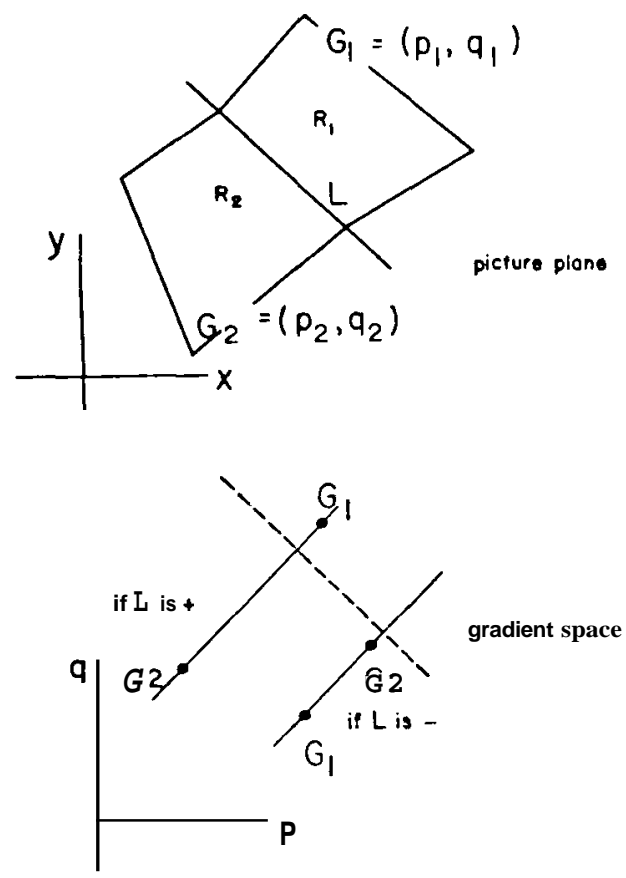

Figure 3: Properties of dual lines. If two plancs mect and the intersection linc is projected as a picture line $L$, then the gradicnts of the two plancs are on a gradient-space line which is pcrpendicular to $L$ 


\subsection{Image Intensity}

\section{1 - IShading}

Grcy-level shading has been neglected or even thrown out in most robotics vision. though it is well known that it gives information on surface curvature. This is partly due to the dominance of binary imagc processing for fast proccssing and partly due to lack of adcquatc theory and techniques for exploiting shading information. Horn [9] did a pioneering work in shape-from-shading theory. Figurc $\mathbf{4}$ shows a simple modcl of imaging: it consists of a point light source, a surface patch, and a viewer. In general the intensity in the image corresponding to the surface patch is a complex function of illumination position, surface material, surface position. surface orientation, vicwcr position, ctc. Iet us assume. for simplicity, a Lambcrtian surface (ie. perfectly uniform diffuse reflection) and a parallcl incident light (ie, a distancc point source). The obscrved intensity $I$ which corresponds to the surface patch is given by,

$$
I=I_{0} \rho \cos (i)
$$

where $I_{0}$ is the intensity of the incident light, $\rho$ the reflectance of the surface, and $I$ the incident anglc which is made by the incident light and the surface normal.

In order for this cquation to be usable in vision. we necd to convert it into the imaging coordinate framc. 'This can be done by using the gradient spacc. The surface normal of the patch is $n=(p, q, 1)$ and the dircetion vector of the illumination is cxpressed as $\mathbf{s}=\left(\mathbf{p}_{\mathrm{s}}, \mathrm{q}_{\mathrm{s}}, 1\right)$. Since $\cos (i)=\mathbf{n} \cdot \mathbf{s} /|\mathbf{n}||\mathbf{s}|$,

$$
I(x, y)=I_{0} \rho\left(p p_{s}+q q_{s}+1\right) / \sqrt{p^{2}+q^{2}+1} \sqrt{p_{s}^{2}+q_{s}^{2}+1}=R(p, q)
$$

In this way. the obscrved intensity $I(x, y)$ at an imagc point $(x, y)$ is cxpressed as a function $R(p, q)$ of the surface oricntation $(p, q)$ of the corrcsponding surface point. Figurc 5 shows the loci of cqual-intensity gradicnts $R(p, q)=l$, for the case $\left(p_{s}, q_{s}, 1\right)=(0.7,0.3,1)$; i.c., the light comes from slightly above and right of the vicwing angle. Figurc 5 is called a reflectancc map.

It is worthwhile to note the significance of the representation like the reflectance map (or cquation (5)) as compared with cquation (4). Fquation (4) represents the physical rulc in imaging as vicwed from a third person who obscrves the imaging process. In contrast. cquation (5). though representing the same rulc. is in the vicwer's cerrdinate framc. 'This is essential for using the rulc to interpret the images because the images arc recorded in that cerordinate framc.

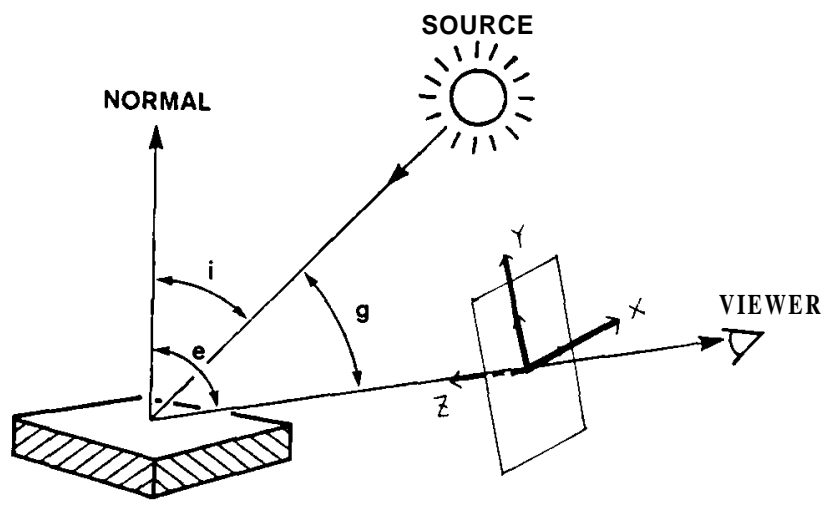

Figure 4: A simple reflection and imaging model 


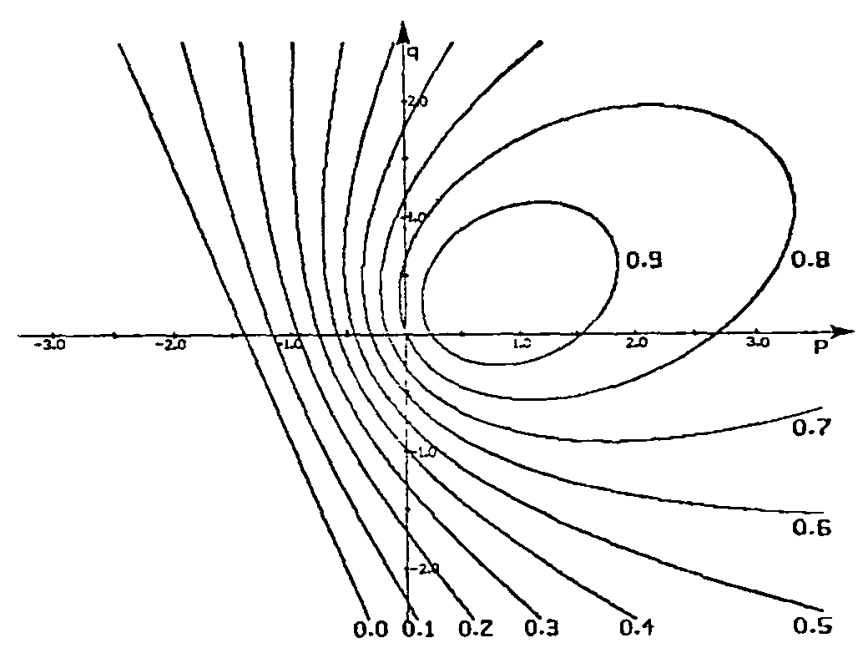

Figure 5: A reflectance map for a Lamberian surface illuminated by parallel flux of light from the direction $(0.7 .0 .3,1)$.

The rcflcctance maps can be used in a few ways. One is for shapc-from-shading: given an imagc of an objcct. compute the shape of the object using the shading information. This can be accomplished by assigning to cach pixcl $(i, j)$ in the imagc a gradient $\left(p_{1}, q_{11}\right)$. The reflectance map alone docs not give enough constraints to uniquely determine the gradient at each point: i.c.. $\mathrm{R}^{1}: l \rightarrow(\mathrm{p} . \mathrm{q})$ is not a unique function. Here we nced additional constrants. Ikcuchi and Horn [12] demonstratcd a numerical shape from shading by assuming surface smoothness. They obtaincd the solution by minimizing the following.

$$
\mathrm{F}=\sum_{1} \sum_{j} \mathrm{~F}_{\mathrm{ij}}=\sum_{\mathrm{i}} \sum_{\mathrm{j}}\left[\left\{I(\mathrm{i}, \mathrm{j})-\mathrm{R}\left(\mathrm{p}_{\mathrm{ij},} \mathrm{q}_{\mathrm{ij}}\right)\right\}^{2}+\lambda^{2}\left\{\left(\mathrm{p}_{\mathrm{ij}}-\overline{\mathrm{p}}_{\mathrm{ij}}\right)^{2}+\left(\mathrm{q}_{\mathrm{ij}}-4_{1 \mathrm{j}}\right)^{2}\right\} 1\right.
$$

'l'he first tenn in E,, Corresponds to the difference between the observed and expected intensities. The sccond term approximates the Laplacian of the surface orientation and thus provides index of non-smoothness. In order to solve this minimization we further need boundary conditions: certain places in the image where the surface orientations arc known. Occluding contours proside such boundary conditions. The surfacc orientations of those pixels ;it the occluding contours are known bccause the surfacc normal there is perpendicular to the line of sight ( $/$ axis) and the occluding contour projectcd onto the image. Using all thesc constraints 3D shape recovery from a grev-level imagc was dcmoiistrated.

Another use of the reflectance map is photometric stereo[35]. Multiple images of an object are taken by the camera at one position. but with different lighting directions. At each pixcl position. each image prosides constraints on surface orientation according to the reflectance map. which corresponds to that lighting condition. Threc or more images can determine the surface orientations uniquely. l'his method eliminates the so called correspondence problcm in stcrco. bccausc the imagcs arc taken from a single position and thus are registered. It suggests use of dynamic clever control in lighting to inspect surface texture and anomalies in such applications as soldering and casting inspection.

The reflcetion propertics of materials are complicated. and rather than analytical forms. they are often measured in forms such as the bidirectional reflectance distribution function (BRDF) or goniophotometric measurement. lhere have becn developed computational procedures to convert such data into reflecrance maps [10] [30]. These techniques make it possible to apply the reflectance map method to robotics tasks, because the environments are usually constrained and surfacc propertics arc known or measurable. 


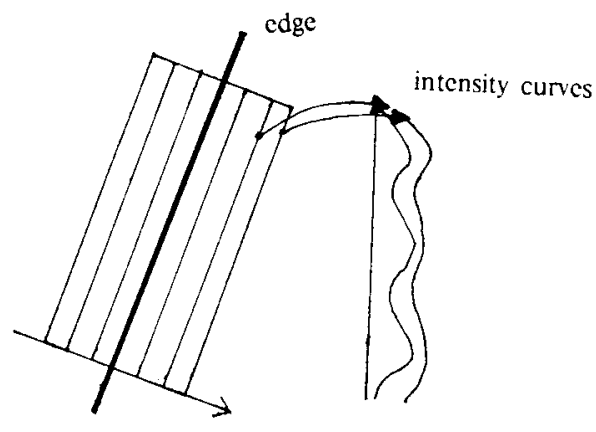

Figure 6: A stripe region around an cdgc. in which columns of intensity curves are taken for correlation.

\subsubsection{Classification of Edge Types}

We have notcd that so called image edges (discontinuity of image intensity) can correspond to many types of scenc cdgcs. The most represcnwtive types are:

\section{Trpe Discontinuous Sccnc Fcaturc}

Convex/Concave Surface orientation (Continuous distance)

Occluding Distance (Different surfaces)

Cast Shadow Illumination (Same surfacc)

Self Shadow Illumination derivative

Pattem Reflectance

If we can classify edges in the image into ihese types. it will make it far casicr to analyze the 3-dimensional shapes of objects from the imige. For cxampic, the ohject shape can be found from occluding boundarics without heing confused by non-shape related edges: and stereo matching would be much casicr because the cdge types tell what kind of different appearance should be cxpectcd on cither side of an cdgc in making correspondence.

Initially. use of cdgc profiles [9] or intensity derivatives near the cdgc [3] was suggested for cdge classification hased on consideration of micro structures near the cdgc. Recently Fischler and Witkin [7] studied an interesting method to detect occluding boundaries and cast shadow edges in the imagc. Consider strip regions along an cdge as shown in Figure 6 and take columns of intensity curves taken parallel with the cdge along its Icngth. A scquence of linear regressums is performed between cach pair of consecutive intensity curves. As a result a normalized corrclation coefficient is obtaincd. together with additive and multiplicative regression terms. cach as a function of the location across the edgc. An occluding boundary is indicated by a sharp notch in an otherwise high correlation at the nominal edgc location. A cast shadow boundary is indicated by high corrclation maintained across the cdgc with a sharp spike or notch in the additive and multiplicative regression term due to transition between shadow and nonshadow sides.

Justification of this method is given by the following simplified arguments. At the occluding boundary we are looking at different surfaces on cach side. Thus the image properties across it should not be corrclatcd. $\mathrm{At}$ the shadow boundary. illumination changes but the surface is the same. Thus image intensities across it should be corrclatcd with change only in cither magnitude or scale. This classification mcthod rests on the principle that the coherence in the imagc intensity reflects the real coherence in the scene. 


\subsection{Geometry}

Geometry is another important physical level of knowledge which governs the vision process and from which constraints can be extracted.

\subsubsection{D Shape}

Two dimensional shapes of rcgions (i.e., projection of surfaces) in the image convey information about the thrce-dimensional shape of an object in the sccnc. This is illustrated by such simple drawings in Figurc 7. Figurcs 7(a) and (b) are topologically the samc and the slight difference in the 2D shape of the lower two regions results in different perceptions "cube" and "trapezoidal block". In fact, even such simple figurcs as Figurcs 7 (c) and (d) alrcady invoke the pcrecption of surface oncntations. Certain gcometrical propertics should be the source of that perception. These phenomena may have becn often studicd in their psychological aspects. but until recently very little has becn formulated in a manner usable for machine vision.

Kanadc [15] demonstratcd a systcmatic method to rccovcr 3-dimensional shapcs from a single view by mapping image propertics into shape constraints. The 2I) shape property of Figure 7 (c) and (d) is one of the propertics he studicd. It was named skewed symmetry, because thcy arc interpretcd as symmetric figurcs vicwed obliquely. In other word, whercas in the usual symmetry reflective correspondences arc found along the dircetion perpendicular to the symrnctry axis, in the skewed syrnmetry it is is found along the direction not necessarily perpendicular to the axis, but at a fixcd angle to it. Formally. such shapes can be defincd as $2 \cdot 1$ ) $\wedge$ ffinc transforms of real symmetrics.

'I'herc arc a good body of psychological cxpcriments which suggests that human observers can perceive surfacc oricntations from figures with this propeny. 'This is probably becausc such qualitative syrnmetry in the image is often duc to rcal symmetry in the scenc.

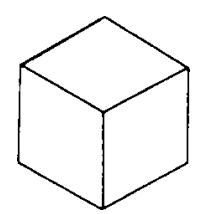

(a)

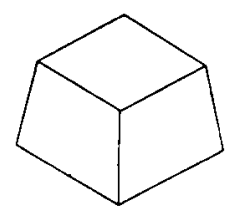

(b)

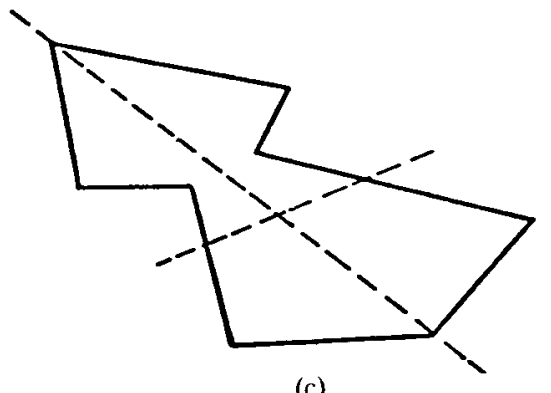

(c)

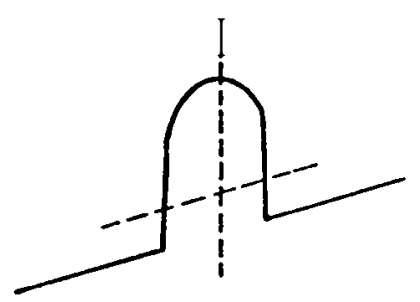

(d)

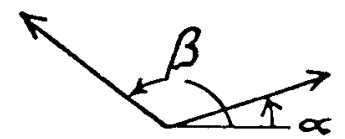

(e)

Figure 7: (a) (b) Simple line drawings: (a) "cube": (b) "trapezoidal block": (c)(d) skcwcd symmctry: (c) axes of skcwed symmctry of(c) 


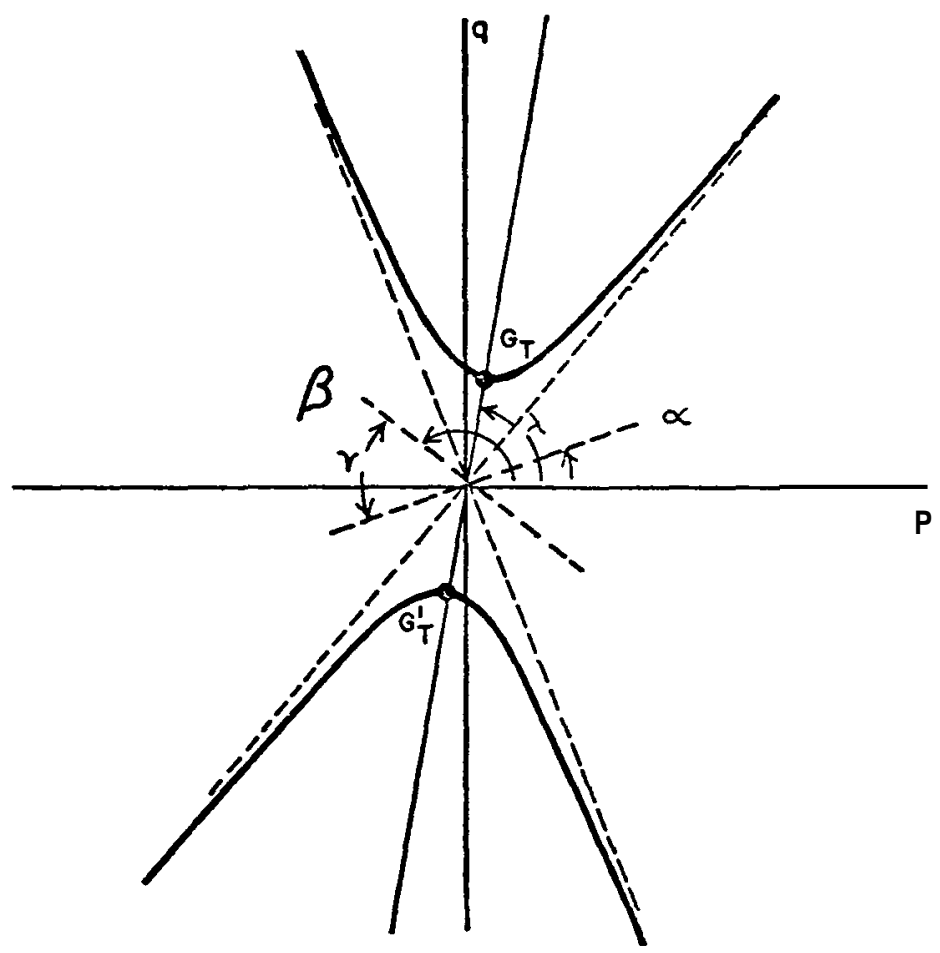

Figure 8: The hypcrbola ofeq. (8) corresponding to Figurc 7(c). The axis of the hyperbola is the bisector of the obtuse angle made by $\boldsymbol{a}$ and $\beta$. The asymptotes rnake the same angle as the acute angle made by $a$ and $\beta$. 'The tips or vertices $G_{T}$ and $G_{p^{r}}$ of the hypcrbola represent special oricntations with intercsting propertics. Lispecially, since they arc closest to the origin of the gradient spacc. and since in gencral the distance from the origin $t o$ a gradient $(p, q)$ represents the magnitude of the surface slant $G$, and $\mathbf{G}_{\mathrm{q}, \mathrm{c}}$ correspond to the least slanted oricntations that can produce the skewcd symmetry in the picture from a real symmetry in the scene.

Now let us associate the following assumption with this imagc property: "A skewed symmetry depicts a real symmetry viewed from some unknown view angle." Notc that the converse of this assumption is always true in orthographic projection. As shown in Figurc 7(c), a skcwcd syrnmetry detincs two dircetions: Ict us call them the skewed-symmetry axis and the skcwed-transverse axis, and denote their directional angles in the picture by $\boldsymbol{a}$ and $\beta$, respectively. Let $G=(p, q)$ be the gradient of the plane which includes the skewed syrnmctry. In gencral the $2-D$ unit vector e in the direction $\gamma$ is $\mathbf{e}=(\cos \gamma, \sin \gamma)$. From (3), the 3 -D vector corresponding to $\mathbf{c}$ on the plane in the space is given as:

$\mathbf{u} \gamma=(\cos y . \sin y .-(p \cos \gamma+q \sin \gamma))$.

The assumption about the skcwed symmetry demands that the two 3D vectors $\mathbf{u}_{\alpha}$ and $\mathbf{u}_{\beta}$ be perpendicular in the 3D space: i.e., their inner product vanishes, $\mathbf{u}_{\alpha} \cdot \mathbf{u}_{\beta}=0$, or:

$$
\cos (\alpha-\beta)+(p \cos \alpha+q \sin \alpha)(p \cos \beta+q \sin \beta)=0 .
$$

By rotating the p-q coordinates by the amount $\lambda=(\alpha+\beta) / 2$ into the $\mathrm{p}^{\prime}-\mathrm{q}^{\prime}$ coordinates so that the new $\mathrm{p}^{\prime}-\mathrm{q}^{\prime}$ axes 
are the bisects of the anglc made by the skewed-symmetry and skewed- the skewed-symmetry and skcwcd-transverse axes, it is easy to show that (8) represents a hypcrbola in the gradient spacc shown in Figurc 8. That is. the skewed symmetry defined by $\boldsymbol{a}$ and $\boldsymbol{\beta}$ in the picture can be a projection of a real symmetry if and only if its surfacc gradient $(p, q)$ is on this hyperbola. The skcwcd symmetry thus imposes a one-dimensional family of constraints on the underlying surface orientation. Figure 9 illustrates how this skewed symmetry constraint can be used to rccovcr the shapc of "cube" from the image.

The same approach was extended to other properties: parallel lines, affine-transformable patterns. and textures [17]. We can summarize the assumptions used in these cases: regular properties observable th the picture are not by accident, but are projections of some preferred corresponding 3-0 properties. Figure 10 lists instances of this principle of non-accidental image regularity. Note also that the principle used in classifying the edge types in the proious section is also the same effect: the coherence in the image reffects the real coherence. Since the mapping from the picturc domain to the Scene domain is one-to-many (ambiguous), we nced to rely on this type of general assumptions or task-specific constraints to rcsolvc the ambiguity.

\subsubsection{Shadow}

Shadow gives good clucs on spatial relationship between objects and surfaces. Acrial photo interpreters makc much use of it in figuring out. for cxamplc. the height of the objects. Lowe and Binford [19] demonstrated the reconstructing of the shape of an airplanc by using shadow information. They first paired shadow-making cdges and casted-shadow cdges on the ground by assuming the ground planc and the sun anglc. Then the height of the airplane along the contour made of shadow-making cdges was estimated, which gave the shape of the airplanc.

Shafer and Kanade [31] investigated a general and compact gradient-space representation of geometrical constraints given by shadow. Figurc 11 shows a basic shadow prohlcm. It consists of the parallel-light illuminator $I$, the shadow making (occluding) surfacc $S_{0}$ and the shadow surfacc $S_{S}$. 'l'he problems includes six parameters to be cornputed: the gradient $G_{0}=\left(p_{0}, q_{0}\right)$ of $S_{0}$, the gradient of $G_{s}=\left(p_{s^{\prime}}, q_{s}\right)$ of $S_{s}$ and the direction of illumination $\left(p_{1}, q_{1}\right)$.

This problem can be studicd by considcring two other surfaces $S_{11}$ and $S_{12}$ (and their gradients $\mathbf{G}_{11}$ and $G_{12}$ ), cach of which includes a pair of shadow making and casted shadow cdges: for cxarnple, $F_{01}$ and $1 \vdots_{s 1}$ definc $S_{11}$. Notc that $S_{\mathrm{f}}$ and $S_{\mathrm{s}}$ makc a concave edge along $\mathrm{F}_{\mathrm{S}}$, and so do $S_{\mathrm{V}}$ and $S_{\mathrm{s}}$ along $\mathrm{F}_{3}$. Now threc constraints are provided from the basic shadow problem gcomctry: 1) I he angle $G_{0}-G_{11}^{2}-G_{s}$, which comes from the angle $!_{01}-1 !_{s 1} ; 2$ ) 'l'he angle

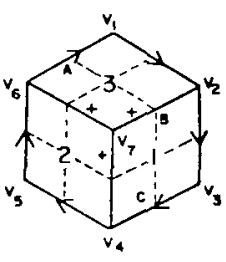

(a)

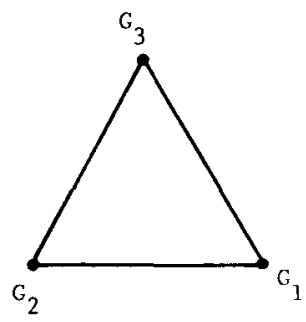

(b)

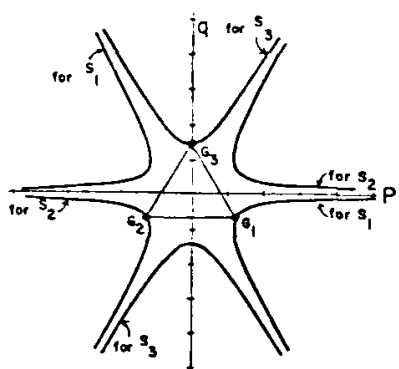

(c)

Figure 9: (a) A labcled line drawing: the dotted lincs show the axes of skewcd symrnctry. (b) The constraints on the gradients of the threc surfaces duc to their interconncetion: the gradients form a triangle in the gradicnt space whose shape and oricntation should as shown. but the location and the size arc arbitrary. (c) 'l'he hyperholas shown correspond io the skewcd symmetries of the threc regions. 'l'he prohlcm is thus how to place the triangle of (b) $)$, by translation and walc changc. so that so that cach vertex is on the corresponding hyperbola. The locations shown is prover to be the only position. and the resultant shape is a cubc. 


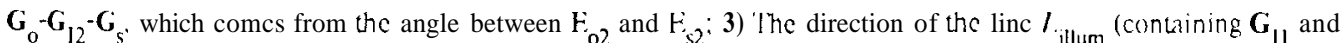
$G_{12}$ ). which comes from the dircetion of $F_{11}$ (line containing the two vertices $V_{o 12}$ and $V_{\mathrm{s} 12}$ ). We would thcreforc cxpect that threc parametcrs must be given in advance. and the other threc can he computed ficun the gcornctry. Figurc 12 shows a construction for the case that the dircction of illumination (actually the relative depth component of illumination vector - one parameter - is given $)$ and the the orientation of shadow casted surface $\left(G_{s}\right)$ arc known.

The basic shadow gcometry provides threc constraints, and thus thrce parameters have to given by other means to solve the problcm. It is interesting to compare this situation with the situation without shadows: an image which only depicts $S_{0}$ and $S_{\mathrm{s}}$ intcrsccting along $\mathbf{F}_{\mathrm{o}}$. Here. there arc four paramctcrs $\left(\mathbf{G}_{0}\right.$ and $\left.\mathbf{G}_{\mathrm{s}}\right)$ to compute, and one constraint from the image $(\mathrm{E}$,$) . so threc picces of information arc still necded in advance. With shadows, the Same$ numher of a priori parametcrs are necded, but one of them can be a description of the light source position instcad of a description of a surface oricntation. The gcometrical significance of shadows is that thcy allow information about the light source to be used to solve the problem as a substitute for information about the surface orientations themselves.

\subsection{Texture}

Pcrception of depth and surface from texture gradient has been studicd by psychologists. Recently, Kcndcr [18] developed a vcry powerful computational paradigm for shape from texture. His central idca is a normalized texture propcrty map (NTPM), which is again for mapping image features (texture in this case) into scene properties.

I.et us show an example of NTPM for length. Suppose we have a texture pattern shown in Figurc 13. which is madc of line segments with two orientations: the horizontal ones with length $\mathrm{L}_{2}$ and the diagonal ones (45") with length $\mathbf{L}_{1}$. Consider in general a line segment in the image whose direction is of angle $\gamma$ with the $x$ axis and whose length is 7 . If that line segment is on a plane whose gradient is (p.q), what is the real length of the 3-dimensional line in the scene? From (7). $/ \mathrm{u}$ is the corresponding $\mathbf{3 D}$ vector, and its $3 \mathbf{D}$ length is

$$
I .(\gamma \cdot I)=l|u|=I \sqrt{1+(p \cos \gamma+q \sin \gamma)^{2}}
$$

I $(\gamma, l)$ is the NTPM for a line segment with slope $\gamma$ and length $l$. As with the reflectance map. we can represent (9) as a set of contours in the gradient space, $\mathrm{L}(\gamma, I)=\mathrm{I}$. cach corresponding to such (p,q) 's that the 30 ) lincs which arc on the surface and which will be projected onto the image as a linc of length $l$ and angle A arc of length I. Figure 14 shows the NTPM for $\gamma=45^{\circ}$. In gencral. the NTPM is a function of surface oricntations. and its value rcprcsents a sccnc propcrty (c.g., 3D line length) that the scene constitucnt in that surface orientation should take if the observed image property (cg. 2I) linc Iength) comes from it. In other word, it represents deprojected scene properties from image.

$\begin{aligned} \text { Picture } & \text { Scene } \\ \text { Parallel in 2D } & \text { Parallel in 3D } \\ \text { Skewed symmetry } & \text { Symmetry } \\ \text { Similar color edge profile } & \text { Similar physical edge property } \\ \text { Matched T } & \text { Interception } \\ \text { Aff ine-transformable patterns } & \text { Similar or congruent patterns } \\ \text { Gradient in } & \text { Regularity in } \\ -- \text { Spacing } & \text { Spacing-- } \\ \text {-- Length } & \text { Length-- } \\ - \text { - Density } & \text { Density-- }\end{aligned}$

Figure 10: Instances of the principle of non-accidental image rcgularity. Notice that the rules arc mostly true when going from the scene to the picture. but the other direction is heuristic. 
Figure 11: Basic shadow problem: the suffixes are given to show the correspondences; for cxamplc. $\mathrm{E}_{\mathrm{ol}}$ is a shadow making edge and $E_{s 1}$ is a corresponding shadow edge.

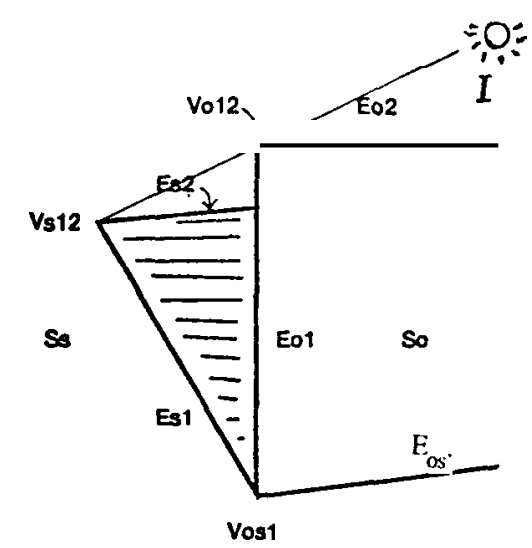

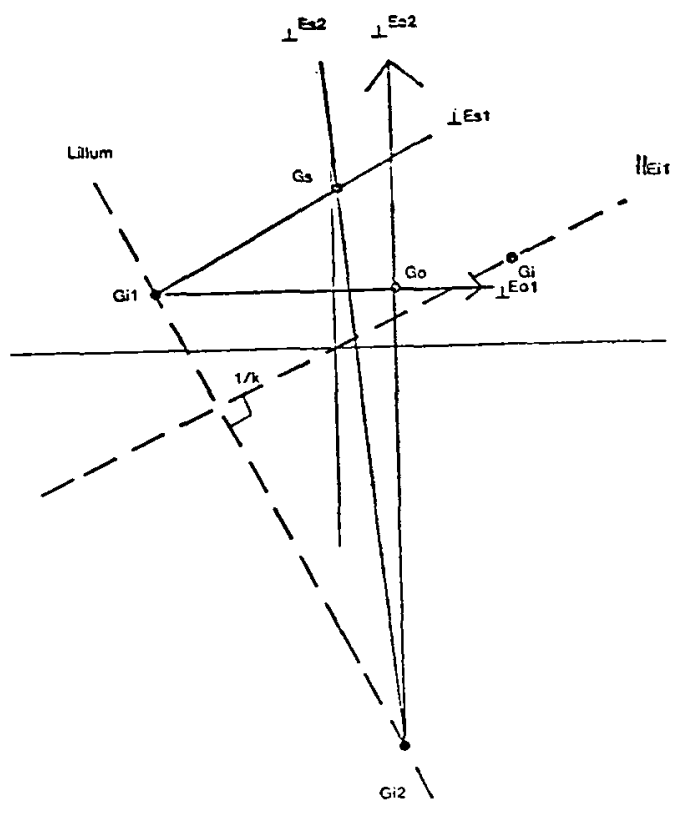

Figure 12: The conscruction in the gradient space for computing $G_{0}$ proceeds as follows:

1. Draw the line parallel to $\mathrm{E}$, through the origin. Plot the given $\mathrm{G}$, (it should be on this line). Let $\mathrm{k}$ bc the distance from the origin to $\mathbf{G}_{\mathbf{I}}$ Draw the line $L_{\text {illum }}$ so that it is perpendicular to $\mathrm{F}_{11}$, opposite to $\mathbf{G}_{1}$ with respect to the origin and at the distance of $1 / k$ from the origin.

2. Plot $\mathbf{G}_{\mathrm{s}}$, which was given. Through this point, draw a line perpendicular to $F_{\mathrm{sl}}$. Where it intersects $L_{\text {illum }}$ must be $G_{11}$. Through $G_{11}$, draw a line per perpendicular to $E_{\mathrm{ol}}$. $\mathbf{G}_{\mathrm{o}}$ must lie on this line.

3. From $\mathrm{G}_{\mathrm{s}}$ draw a line perpendicular to $\mathrm{E}_{\mathrm{s} 2}$. Where it intersects $L_{\text {illum }}$ will be $\mathrm{G}_{\mathrm{I} 2}$. From there, draw a line perpendicular to $\mathrm{F}_{02}$. Since $\mathrm{G}_{0}^{2}$ must lic on this line. the intersection of this line with the final line from step (2) above must be $\mathrm{G}_{\mathrm{o}^{\prime}}$. 


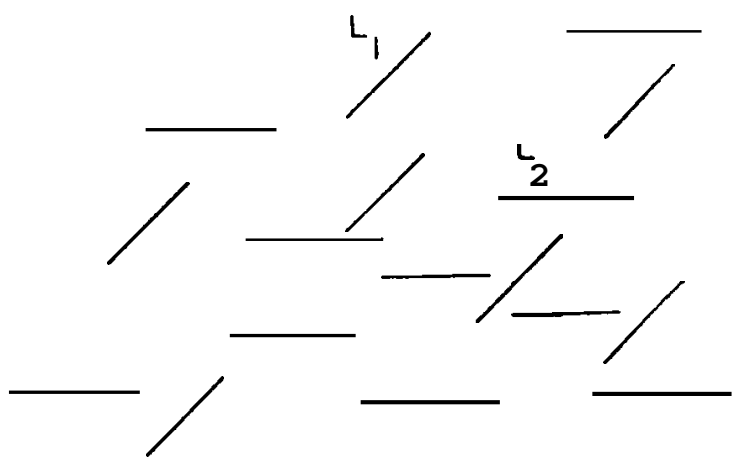

Figure 13: A texture image of linc segments. It is assumed that all line segments are on a planc surface and the their real length arc the samc. What oricntations are possible?

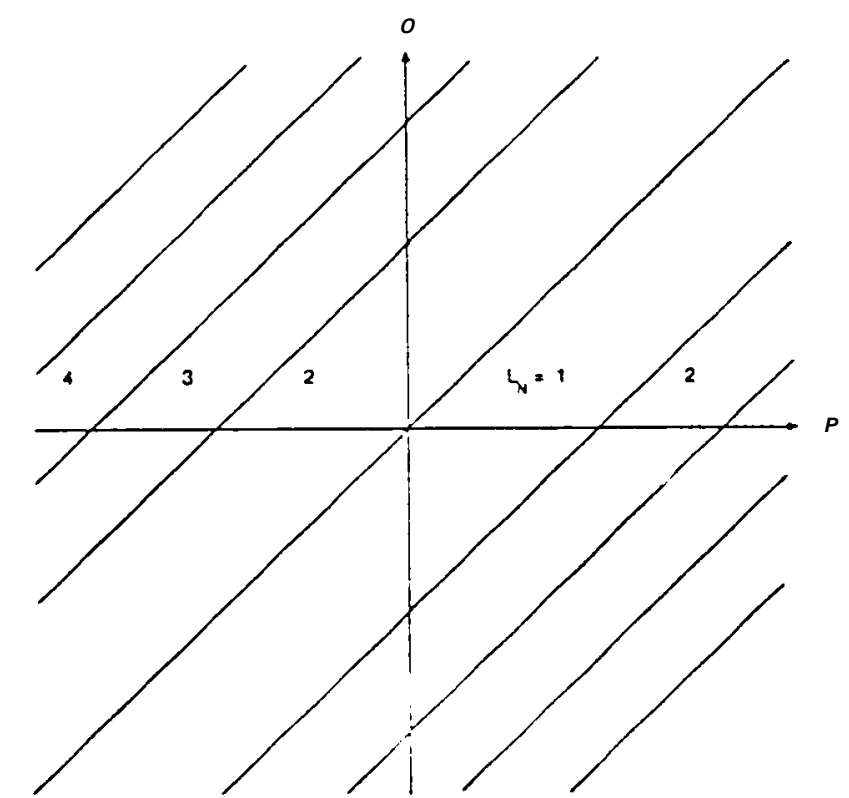

Figure 14: A normalized texture propeny map for Icngth. $I\left(45^{\circ}, 1\right)$. 
In Figure 13. if we assumc that all the linc scgments are on the same planc and arc of the same length in the space, the possihlc oricntations of the surfacc can be obtaincd by

$I .\left(0, J_{2}\right)=J\left(45^{\circ}, L_{1}\right)$

or hy graphically intersecting the NTPM surfaccs. This is hypcrbola in the gradient spacc. Though this is a very simple eximple. the same technique can he uscd to estumate the surface orientations of walls of buildings in outdoor scenes or of mechanical parts with textures. betwecn

We can observe a striking similarity betwecn the case of texture and shading. We can make the correspondence

$\begin{aligned} \text { Shading } & \text { Jexture } \\ \text { pixcl } & \text { texel } \\ \text { Imaging set-up } & \text { scenc constituent } \\ \text { reflectancemap } & \text { NTPMM }\end{aligned}$

In fiact. at in shape from shading, shape recorery of a curred surfice which has a textured pattern on it can be performed by assuming surfice smowhness and regularity in the texture. [17] [11]

\subsection{Remarks}

'I he rcchniqiics and approaches in obtaining and representıng constraints from the physical level of knowledgc arc suggestive to other arcas of robotics which deal with sensing and interpreting natural environments. I'he key idca is to model the projection process and represent 1 in a form that can be uscd for inverse projection in conjunction with other constrants insolved in interpreation. It is noteworthy that the forward projection rules used in Section 2 (reflection or projecture geometry) are simple and fairly well understood. But they are often so local or microscopic that their direci application may result in gigantic unmanipulative cqiiations. hppropriatc representational spaces, such as gradient spacc. enable them to be applied in a macroscopic manner.

\section{3D Model-Based Vision}

'I he theorics presented in the previous section extract natural constraints under reasonable physical, mostly task independent assumptions. In this sense. those methods are model weak. Model-based vision attempts to use taskdependent semantuc constraints. This idea is not new. In fact. ad hoc methods can be regarded as model based. Also two dimensional relationship among parts of objects, represented as cither graphs or procedures. have been uscd to do direct two-dimensional pattern analysis such as face recognition. chest X-ray analysis and region segmentation of aerial photos. Hut xhat wc aim at is 31) model-based vision which can cope with difficultics due to variations of object shapes and vicw angles. Although such perfect systems are probably still far away, we can sec important progress.

An early atrempt in model-based vision [6] used a predetcrmincd set of models with fixed shapes to validate the hypothesired recognition result. Given an imperfect line drawing. the system extracted features and decided what sbjects appeared in what angles in the scene, then gencratcd a line drawing anticipdtcd if the recognition result was correct. It was compared with the input. and if they wcre close the recognition result was correct. otherwise other possibilities wcre pursued.

3-dimensional shape modcls can be also uscd to predict 2-dimensional appcarances of objects beforchand under various lighting conditions. Then interprctation consists of mostly verification (verification vision). An cxample chown in Figure 15 is especially intereseing because the appciananes of stable postures of a part are computed from its 3-dimensional geometric model. [34] First. the cnnvex hull of the ohject is obtaincd, and cach of its surfaces is tested whether it provides a stable support of the object.

A general model-based vision system should have variable or gencric modcls of objects and interprec an input image as instances of the generic model (recall Figure 1) to recognize the specific objects (e.g. Sirc. shape) which appear 
in a spccific manner (c.g. oricntation, distance). The basic difficulty here is the difference in the coordinate frames uscd in the gencric modcls and in the representation obtaincd from images. 'l'hegencric models arc (and should bc) described by viewer-independent representations, whercas the image features and surface representation obtaincd from images are vicwer-dependent. Somehow the two types of representations must be made compatible. Most of the previous systems did this cither by quickly hypothesizing the parametcrs from a very small set of imagc featurcs or by gencrating 2-dimensional appcarances so that they could work totally in the picturc domain. Buth were possible becausc the shapes werc fixcd and limited.

What is necded is a more systcmatic way to access the model and to renson ahout the pirameters. 'l'he ACRONYM systcm at Stanford [4] uses invariant and pseudo-invariant fcaturcs which arc predicted from the given object models. In ACRONYM. an object is modeled by its subparts and thcir affixment (spatial relationships). Volume primitives to represent subparts are generalized cones: A generalized cone is a volume swept by moving a cross section along a 3-dimensional curve (called a spinc). When a cross section is a round dise and it is moved along a straight line with its size varying linearly, a ordinary cone is gencrated. Parameters that specify the gencralized cones and their affixment are given not only by specific values but also by free variables with which rangc and mutual constraints can be associated. In this way one can represent gencric object models which allow variations in size and shape. The imagc fcaturcs that ACRONYM uses arc ribbons (two dimensional stripc) and cllipscs, which can provide an approximation as the projection of the straight spine and the circular cross scction. respectivcly, of the corresponding generalized cylinder.

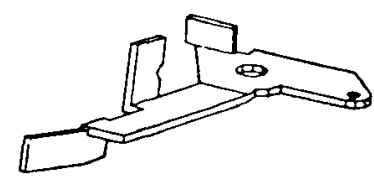

(a)
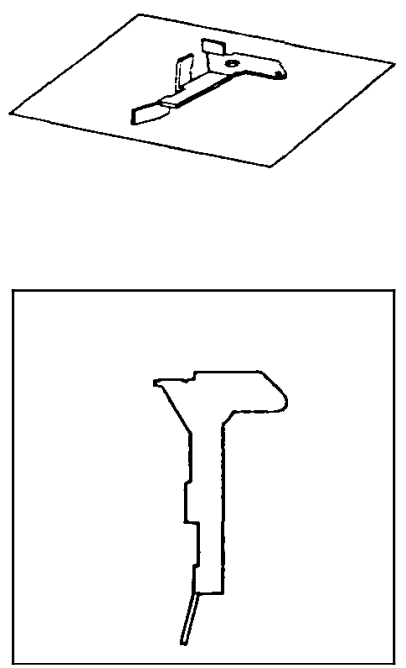

Figure 15: Anticipating the appearances of a parts in stable positions. (a) 3D modcl of a pan: (b) convex convex hull; (c) computed stable positions; (d) silhouettes of stable postures vicwed from overhead.

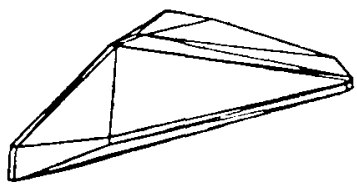

(b)
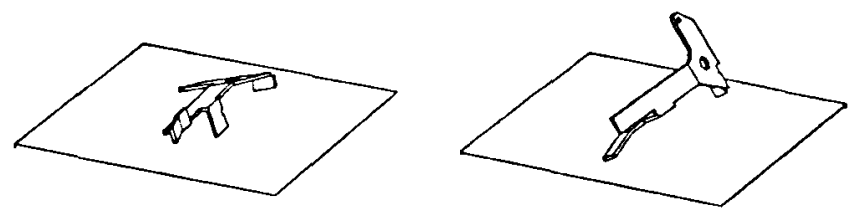

(c)
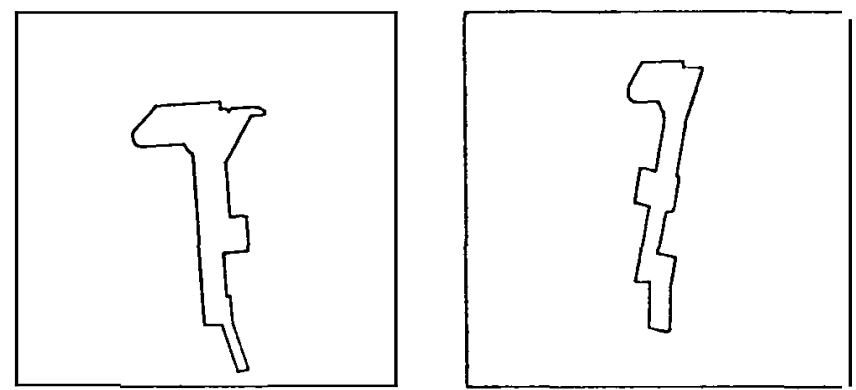

(d) 


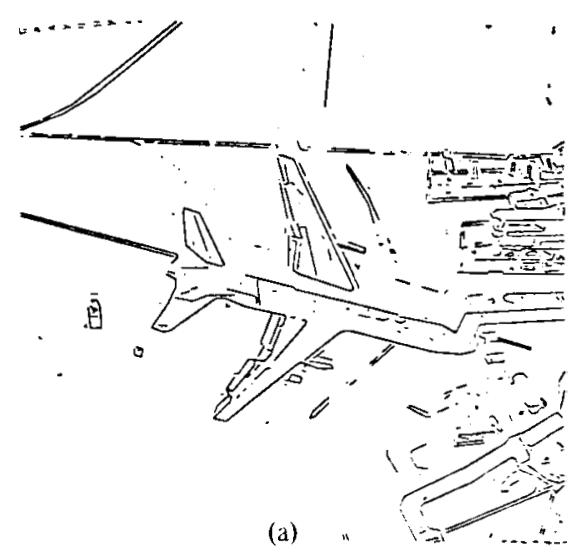

Figure 16: An example of analysis by ACRONYM: (a) Line segments for the input image; (b) instances of class models of Bocing-747a and L-1011s; (c) ribbon description: (d) an L-1011 located.
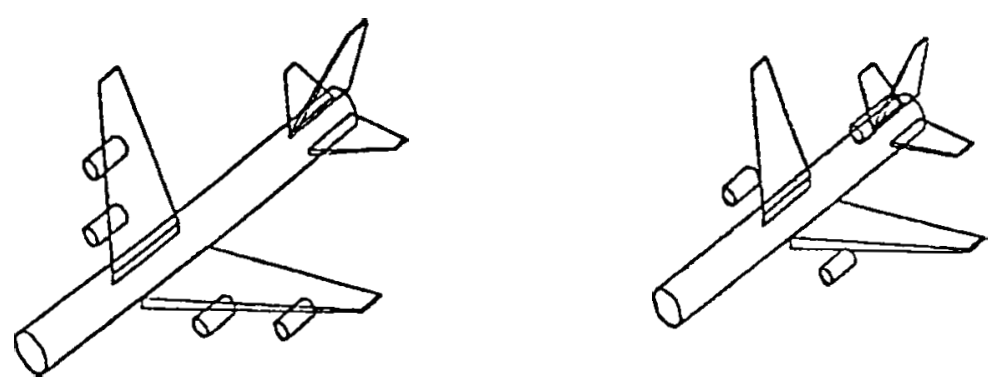

(b)
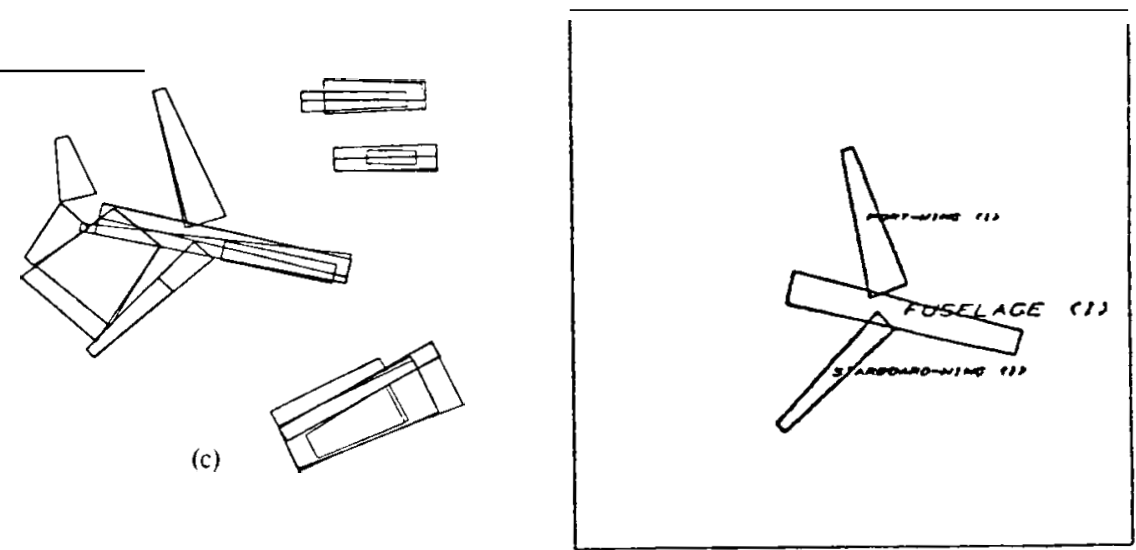

(d) 
One important idea is to predict from the model invariant and pseudo-invariant features of an object. which will be invariantly observable in the image over the modclcd range of variations. They include parallclism, collinearity, and the length ratio and angles between spines. (Hcrc we sce an application of the principle of non-accidental regularity.) They provide a coarse filter for hypothesizing possible objects. For hypothesized objects, the unknown parameters (variations of object shape and distance and orientations of the object) are estimated by the algebraic constraints obtained by associating the observation (such as length and angle in the image) with the anticipated range of its value.

Figure 16 shows an example scene: (a) is the line segmented image extracted from input. (b) shows the instances of modcls of a Bocing-747 and an L-1011; after extracting ribbons (shown in (c)) from the line segment image, an L-101l was identified as shown in (d). This deduction is not based on the size of the image, but on the relationships between the subparts, such as wingspan-to-fuselage-length.

\section{Construction of Scene Description}

The goal of the visual process is to construct the description of the environment which is sensed by visual methods: it must be recognized that this is different from classifying parts of an image, detecting the object existence or scgmenting the imagcs. The difference is most easily understood in the scenario of robot navigation where classification or detection is not enough to plan actions of the robot: it must have a $3 \mathbf{D}$ description of its environment.

At CMU. Kanade and Hcrman [16] arc devcloping a system callcd Incremental 3D Mosaic. which builds a scene description from a scquencc of (stcrco) imagcs. It is currently applicd to an urban scene for building a 3-dimcnsional model of the target arca from low-altitude aerial photos. A single pair of stcreo photos can give only partial information on the scene: only limitcd portions are visible in both images and the stcrco system cannot be perfect anyway. The information must be incrementally accumulated into a consistent description as new images arc available. The information on the portions of the scenc which become visible should be added, and the information on the previously known portion should be uscd to improve the description. either by correcting errors or by increasing the confidence and precision.

Figurc 17 shows a typical sequence. We have a stcrco pair of images (Figurc 17(a)). Lines and junctions are extracted from them (Figurcs 17(b)). Then, junctions and lines are matched. 'l'hey are mostly corners and cdges of buildings. Here we use the fact that buildings are mostly block-shaped, and they have (gravitational) vertical cdges. 'This allows one to hypothesize the changes of junction appearances along the cpipolar line of sterco. and to cope with the difficulty in matching wide-angle stcrco images with large disparity jumps. such as urban scenes. Wc can compute the 3-dimensional locations of the matched junctions and lincs, thus forming wircframes. Figurc 17(c) shows their perspective vicw.

'l'he wireframe representation docs not yet identify surfaces. The next step is to perform reasoning on surfaces. This is done by assigning planar surfaces so that an enclosed object is oblained with the wirefrimes as cdges. The process is similar to obtaining solid objects from wircframes [21], but we assume that our wircframes are not always complete. Figurc 17(d) shows a pcrspective vicw of the constructed blocks objccn. Once we have such a description, we can crop imagc patches from original imagcs to know the normalized appcarances of surfaces (c.g. window patterns). A natural looking display can be generated for the scene viewed from any angle by appropriately transforming such appcaranccs according to surface oricntations. Figure 17(e) is an cxamplc. Notice that parts of surfaces which were not visible in the original images are displayed distinctively as such (i.e. red color).

'l'his kind of description is uscful, for cxamplc. for planning the angles that the ncxt images should take: it is generally better to cover as much of the "red" portions as possible to increase the knowledge of the target area. This scenario of 31) Mosaic is applicable to robot navigation and to change detection in a scene.

\section{Organization and Control of Vision Systems}

A $k c y$ attribute of an image-understanding system is the interaction between high-level knowlcdgc---object models---and low-level knowledge-.- image or scene features. While the general flow of information is bottom-up, from pixcls to image features. to scene fcatures. to object labeling, many systems also have some it lop-down information flow from objcct modcls to image fcaturcs. In the face rccognition program by Kanadc [13]. for cxamplc. a model of the arrangement and intensity characteristics of face components guides all of the low-level processing. After finding 


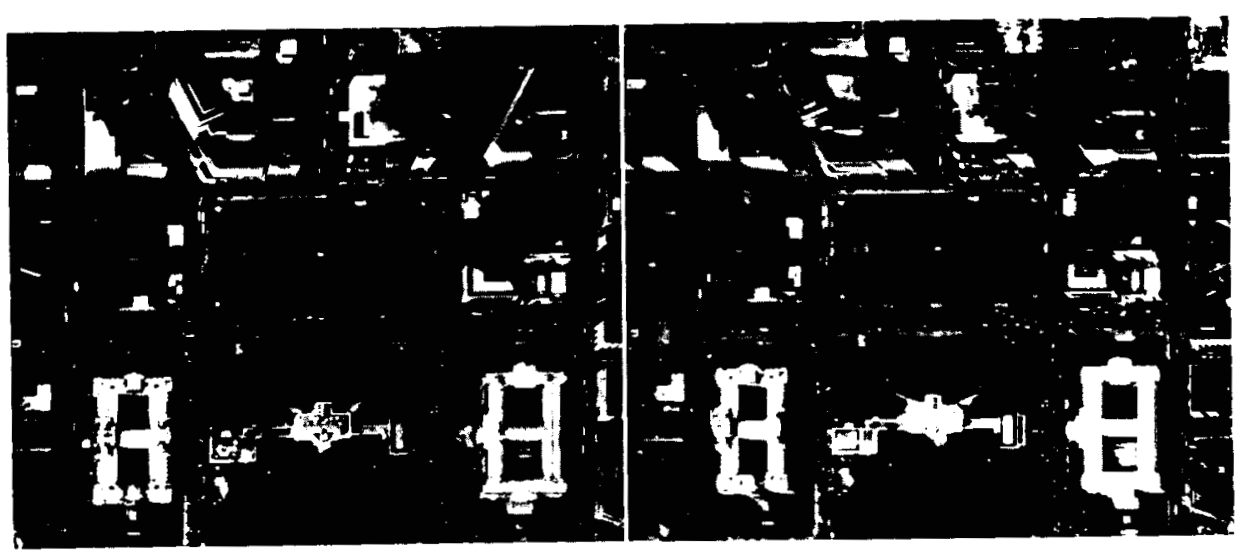

(a)
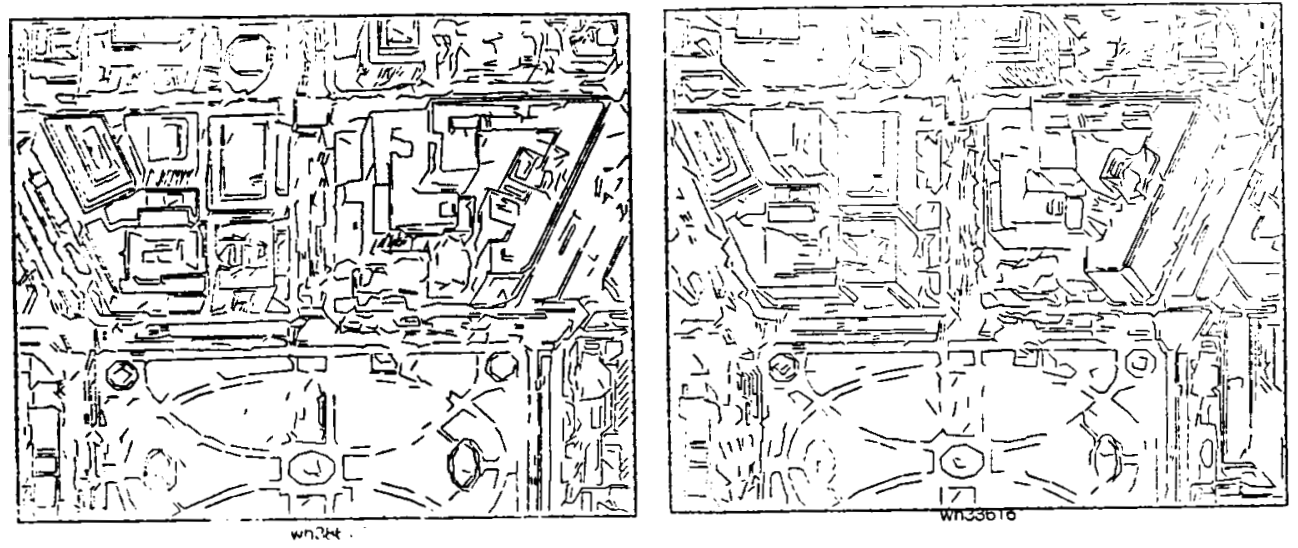

(b)

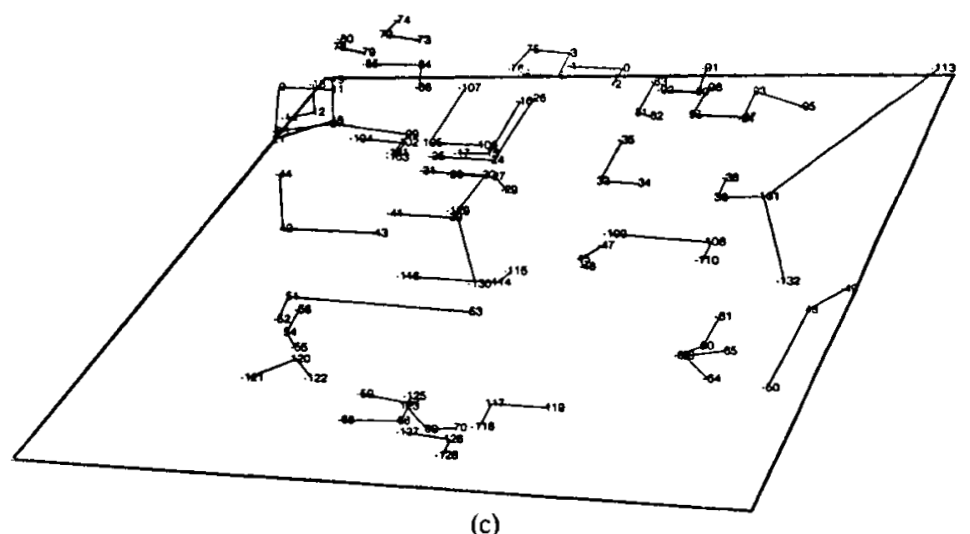

Figure 17: 3D Mosaic: (a) lrnages of right and left vicws; (b) line segments cxtracted; (c) perspective vicw of 3-1) wircfrarncs which arc made by edges obtaincd by stcrco matching: (d) planc-surfaced models of buildings: (c) synthesized image of the scene from the angle different from original angle. 

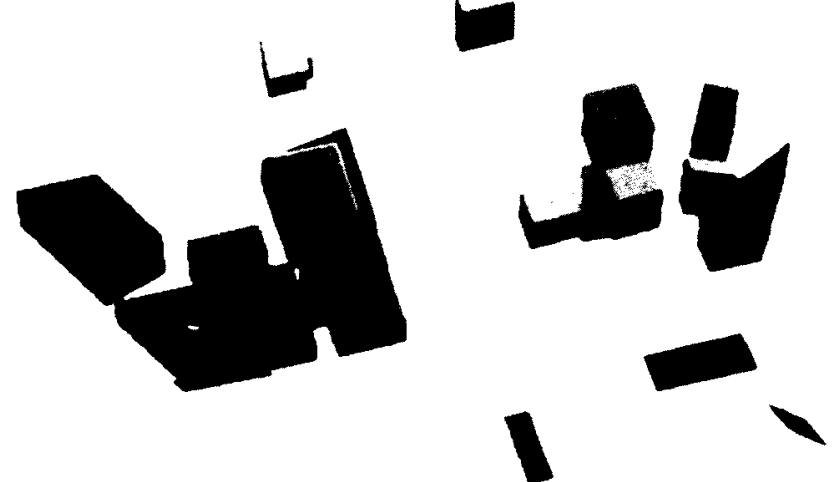

(d)
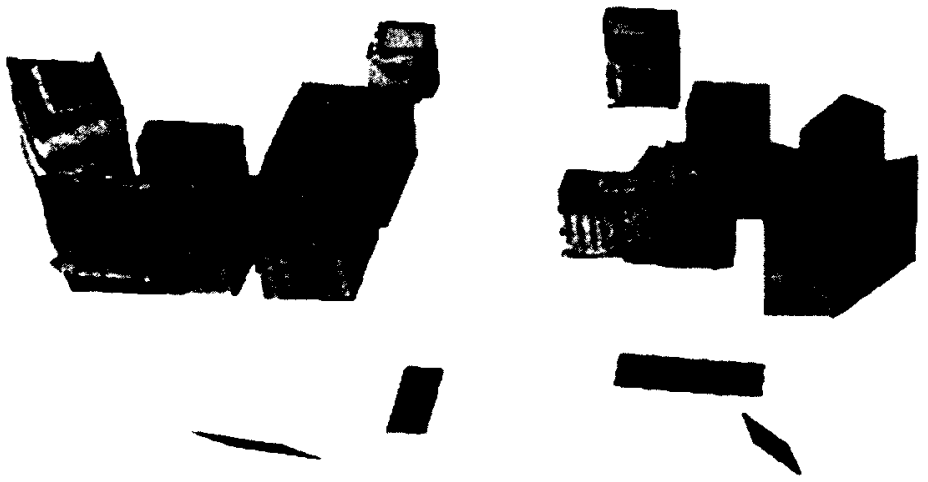

(e)

Figure 17: (continued)

the outline of the head, the program estimates the probable position of the eyes, and look for the dark spots that characterize the pupils in and around the predicted locations. When it fails in finding components with such characteristics, it goes back to the previous steps. assuming a certain error there, and try another possibilities. This model-driven processing can be both efficient and effective. However, programs that depend very much on high-level control of low-level processing tend to be too domain-dependent and respond poorly when viewing conditions change even slightly. In this section we will examine the organization and control of three different types of vision systcms. The following descriptions focus on mechanisms for achieving cooperation and flow of control between low-level and high-level processing stages.

\subsection{Production System Organization for Outdoor Scene Analysis}

Ohta, Kanade and Sakai $[27,26]$ developed a semantic region analysis system for outdoor scenes. Given a color image of outdoor scene, the system assigns semantic labels. such as tree and buildings. to regions. As shown in Figure 18 the system consists of bottom-up part and top-down part. Initially the bottom-up part first segments the image into 


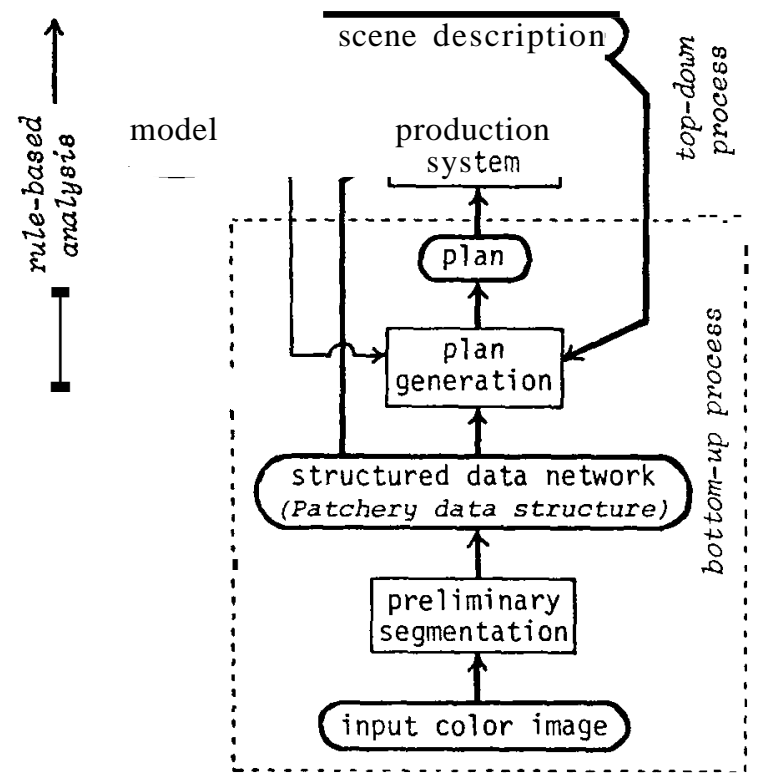

Figure 18: Organization ofthe region-based scene analysis program by Ohta. Kanade and Sakai

homogencous regions by an Ohlander-type region segmentation method [28]. 'The segmentation result is described as a patchcry data nctwork which stores propertics of all the patches extracted.

Then a plan is gencrated from it by sclecting regions by large area, called kcypatches. After merging small patches adjacent to kcypatches. the system tentatively assigns a set of object labels with corrcsponding cstimates of correctness which are computed first from the unary propertics of the keypatches, such as size, shape. and color, and then from the binary relations betwecn them. such as relative positions.

Figurc 19 shows an cxample scenc: (a) is an input color imagc. (b) is the result of preliminary scgmentation, and (c) is the plan imagc. 'l'he first plan obtaincd by using only the unary property rulcs is shown in Figurc 20(a), and Figure 20(b) shows a reviscd one by by using the binary rclations.

The top-down process then starts symbolic interpretation of the image by analyzing detailcd structure of the scene in the context given by the plan. ('l'he system still can change the interpretations in the plan, in which case the bottom-up prtress is re-activated.) 'l'he analysis uses a production systern organization with knowledge of the world (outdoor secne) represented as a set of rulcs. Fash production rulc has a condition pirt and an action part. 'l'he condition part is made of furzy predicates on pronertics of and relations hetwecn regions. The action part is a set of actions to manipulate the database (patchery network, plan, and scene description) to build the scenc description. Fach action is describcd as a form in Lisp. There are TO-DO and IF-DONE rules, corrcsponding to the antecedent and conscquent theorems of PLANNER.

The world model is described as a network of knowledge blocks $\left(K^{\prime} B\right)$ which definc the objects. matcrials, and concepts in the given task world. The production rules are dicided into subsets according to the roles they play in the analysis: For cxample. the subsct for the scene phase analysis is stored in the KB SCENE and the subset to analyze the "sky" is storcd in the K B $S K Y$. 
Control of the production system is handled by an agenda which registers all the executable rules (i.e., whose condition parts are satisfied). The analysis iterates the following three steps:

1. An executable action with the highest Score on the agenda is executed. A patch or a set of patches is interpreted and the database is modified.

2. If a keypatch is interpreted in step 1. the control enters into the Scene phase. The production rules included in the KB $\boldsymbol{S C E N E}$ are activated to (re-)examine the keypatches not yet interpreted. The scene phase. in general. considers the overall structure of the Scene, such as the location of horizon and relationships among objects.

3. Otherwise the control enters into the object phase Corresponding to the object as which the patch has been just interpreted in step 1. The production rules in the corresponding KB are activated. This phase mainly analyze the local structure related to the particular object.

Figure 21 shows how the plan is modified as the analysis proceeds: (a) when the horizon is determined, and (b) when the outline of the building is extracted. Figure 21(c) shows the final labeled interpretation.

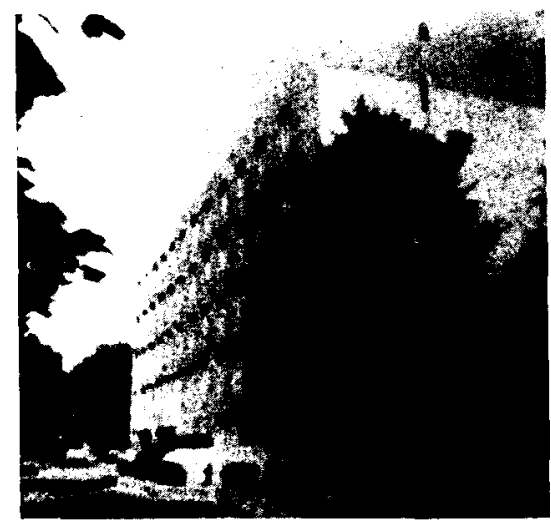

- (a) digitized input scene

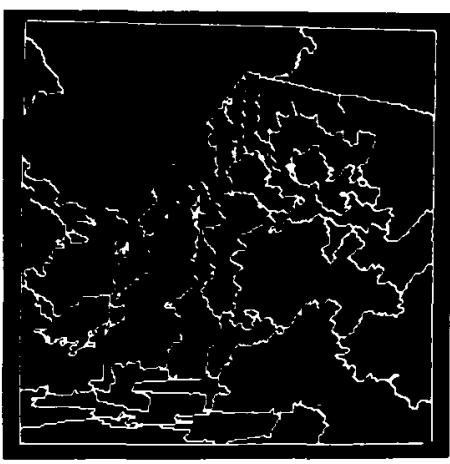

(c) plan image

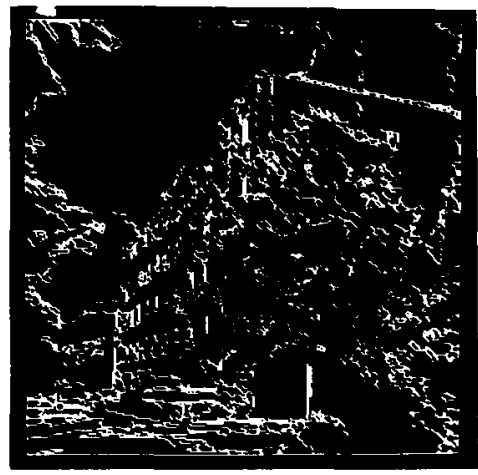

(b) result of preliminary segmentation

Figure 19: An outdoor scene: 


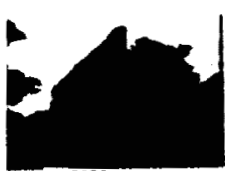

$S K Y$

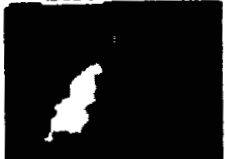

BUILDING

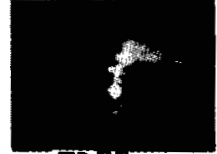

TREE

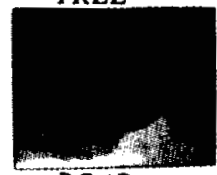

(a)

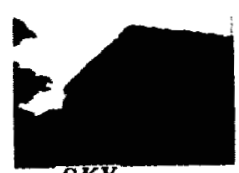

SKY

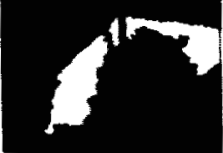

BUILDING

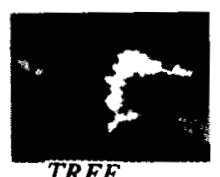

TREE

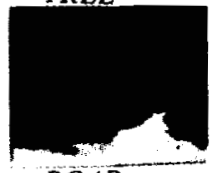

$R O A D$

(b)

Figure 20: Plan

I'he brightness shows the correctness of the assignments: (a) by use of unary properties of regions: (b) after using binary relations

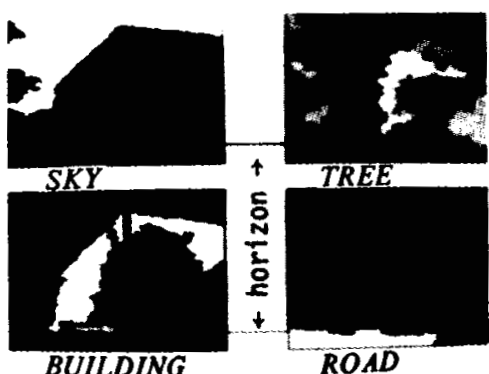

(a)

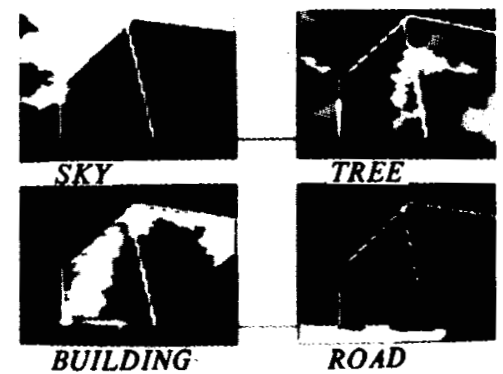

(b)

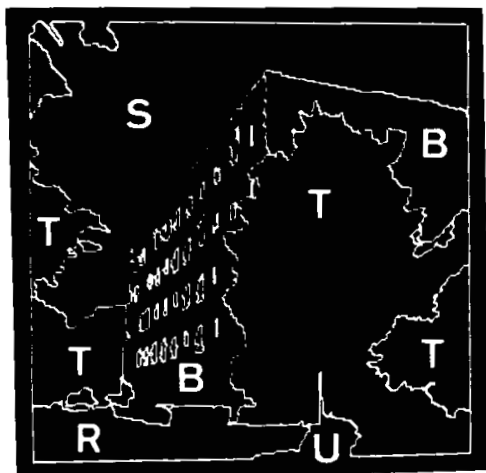

(c)

Figure 21: (a) Plan when the horizm is determined. (b) Plan when the outline of the building is determined. (c) final resulc of interpretation: S: SKY; T: TREF: R: ROAD; B: BUILDING; U: UNKNOWN 


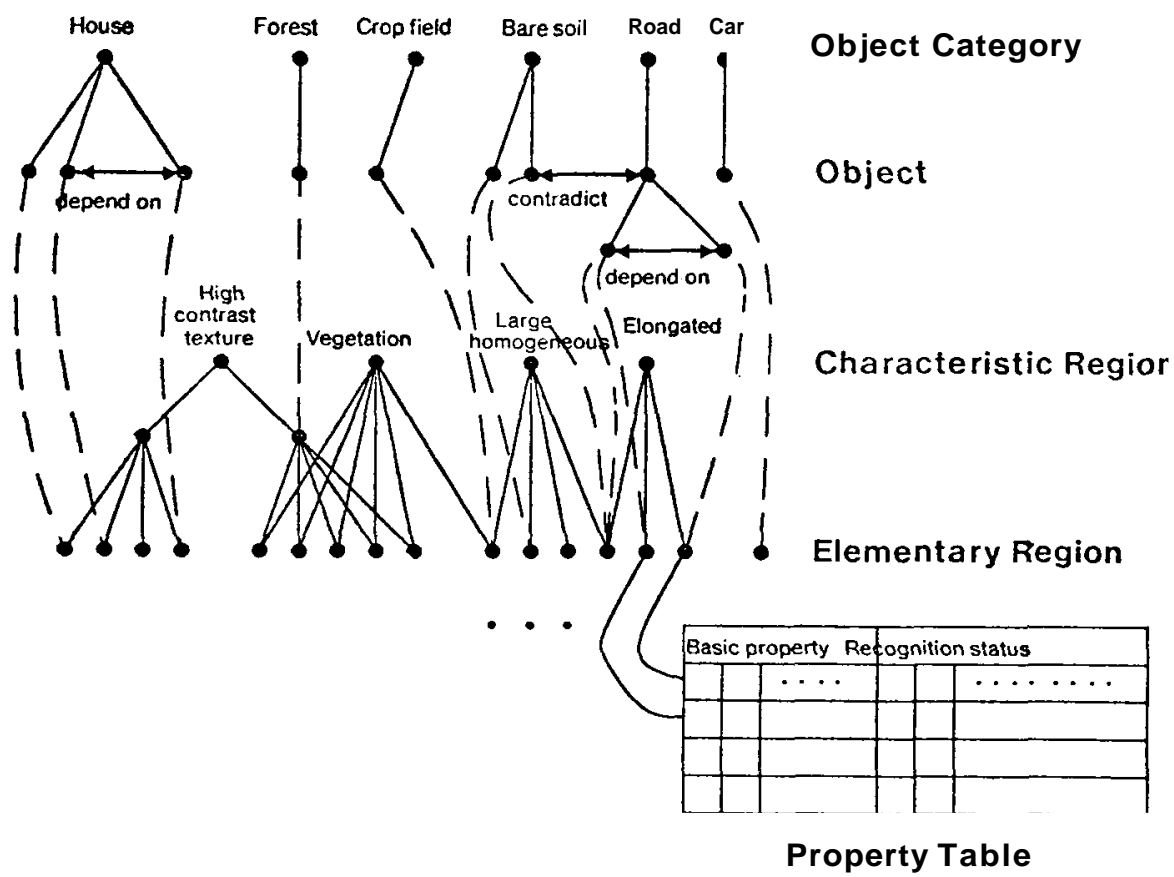

Figure 22: Structure of a blackboard of the systcm by Nagao, Matsuyama and Ikeda

6.2. Blackboard Architecture for Interpreting Multiband Aerial Photographs

Nagao, Matsuyama, and lkeda $[24,25]$ devcloped a systcm that interpreted a class of multiband acrial photos. Their image-interpretation systcm employs multiple. independent knowledgc sources that opcratc on a common, multilevel database. This database. or blackboard. is represented as shown in Figure 22. The abstraction levcls of image information are elementary region. cue region. objecf, and objecf category. Modcls arc describcd in torms of two-dimensional fcatures that can be obscrved in irnagcs. In general. it is not possible to do scene interpretation with two-dimensional models, but it is an acceptable technique for acrial photography becausc the vicw angle is so constraincd that object shapes change little and occlusion is not much of a problem.

The first step of processing is to smooth the imagc. A nonsemantic scgmenter defines a set of elementary

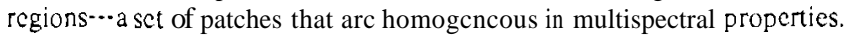

The next stcp is to extract cue regions. The types of cue regions arc large homogencous regions. shadow and shadow-causing regions. clongatcd regions, vegctation rcgions. high-contrast rcgions. and high-contrast vegctation regions. Fach type of cue region triggers one or more object recognizers. Different cue regions may overlap; for cxamplc. high-contrast vegctation rcgions arc simply the interscction of high-contrast rcgions and vegctation regions.

Cuc regions are extracted by screening clementary regions: for cxample. any patch with very low intensity. particularly in red and infrarcd. is classificd as a shadow. An adjacent region with an appropriate boundary on the sunward side is a shadow-makcr. Vegctation regions have a high ratio of infrarcd to red: high-contrast arcas arc aggregations of small clementary regions. Shadow-making regions trigger the housc detcetor. while high-contrast vegetition regions are likely to he considered forest.

Fach elementary region is represented by a node in the lowest lcvel of the blackboard. Nodes at higher lcvels rcprcsent cue rcgions and objects; they arc linked to the clcmentary rcgions they subsurnc. Furthcrinorc. a node can 
have a dependency link to another node, indicating that its intcrprctation was aided by the prior intcrprctation of the other node.

The property table shown in Figurc 22 stores the coordinate rangc. or bounding reclangle, of a rcgion and records whether the region is unanalyzed, recognized, irregularly shaped. or it rejecred. Fach region has only one cntry. which means that there can be only one object hypothesis for a region. The first interpretation of a region is kept until a contradiction ariscs. '1o resolve contradictions. the systcrn delctes the conflicting region interpretation for xhich it is least conffdent. It marks the region as unanalyzcd, restarting the intcrpretation of the region; ohject hypothescs that depend on the delcted node arc themsclvef deleted.

\subsection{Schema-based System: VISIONS}

'l'he University of Massachusetts' VISIONS systern[8] is patterned after the [IE $\Lambda$ RS $\Lambda Y^{\prime}-$-ll specechunderstanding systern[5]. In VISIONS, hypotheses are posted and accessed on a blakkboard by independent procedural knowledge sourceds: $K$.S Their activation and scheduling are under the control of a central executwe. 'The systern has becn tested with outdoor scenes. Figurc 23 outlines the structure of VISIONS.

The blackboard in this system represents a laycred description of the contents of an irnage. The kwest levels represent regions, segments, and vertices; they form a structure callcd an RSV graph.

Preprocessing stages are shown in the left half of Figurc 23. 'There are threc stages of infurmation representation. The first is the image itself, represented by a resolution pyramid (processing cone). 'I'hc second stage comprises separate edge and region analysis. The third stage is a merged representation of the results of a corrclation hetwcen the edge analysis and region analysis. The representations at these low lcvcls arc of image characterissics. rather than of Scene characteristics.

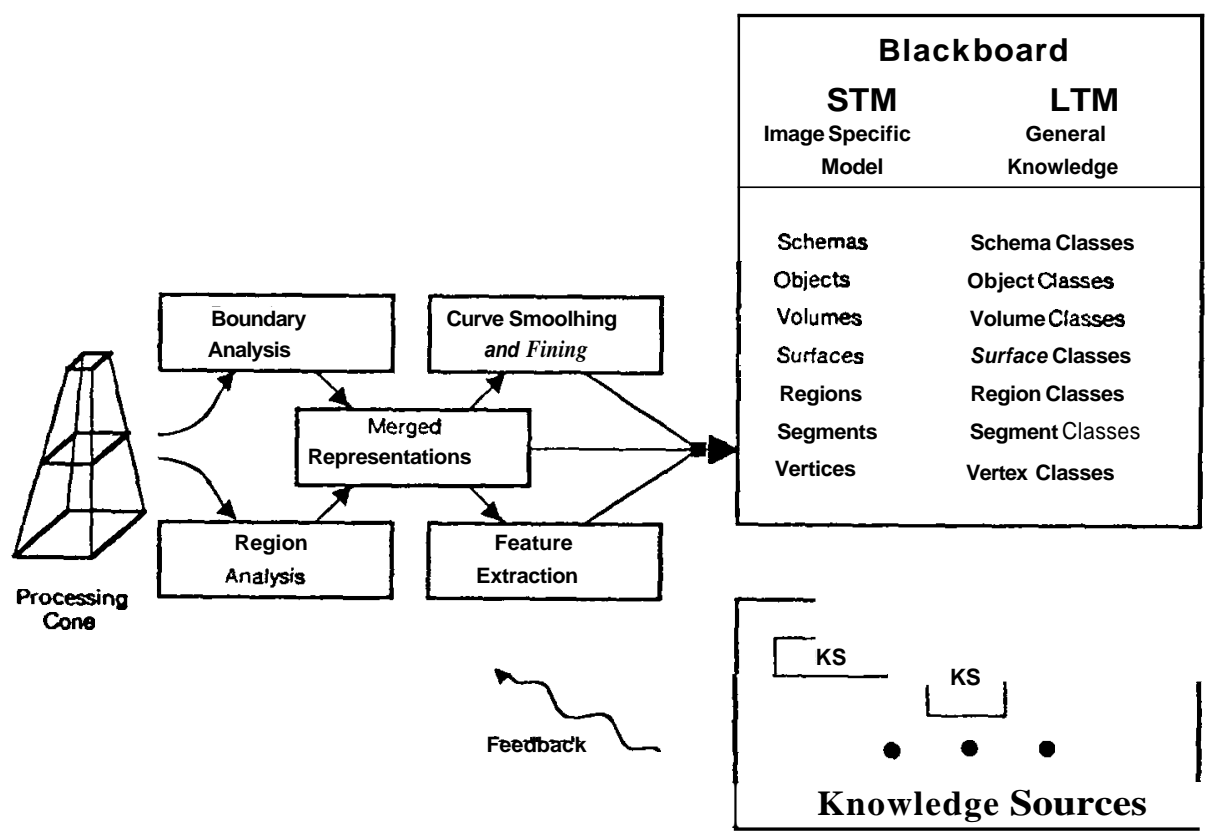

Figure 23: Overview of VISION systcm by Hanson and Riseman 
The next two levels in the blackboard work with surfaces and volumes. At thesc levels. the system attempts to reconstruct the three-dimensional configuration of the scenc. The top two levels work with representations of objects and schemas. At the object level, hypotheses are formed about what the objects in the scenc must have becn to result in the observed imagc. The schema level imposes constraints on the selection of object modcls. There may be office schemas. airport schcrnas, and so on. Schcmas serve the same purpose as Minsky's frames [23].

The blackboard model in Figure 23 illustrates the distinction made in VISIONS betwecn a priori models and image-specific models. though both may be represcnted in the same manner. The a priori models arc storcd in long-fenn memon (LTM), while the unagc-specific models are stored in shor-term memon (STM). Recognizing that they did not have adequate KSs to rnakc surface and volume hypotheses reliably, the designers of VISIONS compensated by relying heavily on top-down hypotheses represented by modcls in LTM. By projecting thcse models into two dimcnsions. they construct RSV-level models ofobjects, and thesc arc matched to the actual image.

VISIONS chooses a KS by traversing a decision tree. Its model builder decides to expand or to devclop a new hypothesis for a model. To expand a model. the level focuser first decides which level of the blackboard to work on. Then, that level is expanded under the control of the node focuser, the node expander. and the node verifier. The focuser selects a node from the blackboard to proccss further, the expander calls a KS to create new hypotheses. and the verifier checks the results for satisfaction of constraints.

\subsection{Remarks}

Some other interesting computer vision systems that interpret natural scenes include: Shirai [3.3] (proccdura] represcntation). Rubin [29] (constraint network representation) and Ballard. Brown and Feldman [2] (query-oricnded analysis). The image/map database MAPS. being developed at CMU by McKeown [22], attcmpts to use mulit-lcve] multi-source knowledgc (such as terrain map and cultural maps) for photo interpretation.

\section{Conclusion}

We have first discusscd a gencral structure of vision. and then identified important arcas to work on for realying a morc capable and gencral vision system than current robotics vision. limphasis has becn put on:

- Computational aspects of vision

- Obtaining constraints from physical and scmantic knowledge

- Multi-lcvel represcntations

- Usc of gencric modcls

- Sccnc descriptions

- Control and information flow in the vision system

\section{References}

1. Artificial Intelligcrec. Special Issue on Vision North-Holland. 1981.

2. Ballard. D. H., Brown. C. M. and Feldman, J. A. An Approach to Knowlcdge-Directed Image Analysis. Computcr Vision Systems. Now York. 1978. pp. 271-281.

3. Barrow, H. G. and Tencnbaum, J. M. Recovering Intrinsic Scene Characteristics from Images. Computcr Vision Systems. New York. 1978,pp. 3-26.

4. Brooks, R. A. "Symbolic Reasoning among 3-D Models and 2-D Images." Artificial Intelligence 17 (1981). 285-349. 
5. Erman, L. D.. Hayes-Roth, F.. Lesser, V. R., and Reddy. D. R. "The HEARSAY-I1 Speech-Understanding Systcm: Intcgrating Knowledge to Resofve Uncertainty." Computing Surveys 12.2 (1980).

6. Falk. G. "Interpretation of Imperfect Line Data as a "Three-Dimensional Scene." Artificial Intelligence 3(1972). 101-144.

7. Fischlcr. M. A. and Witkin, A. P. Recovering Instrinsic Scene characteristics from Images. Tech. Rept. Interim Technical Report. SKI International, Nov., 1981.

8. Hanson, A. R. and Riseman, E. M. Scgrnentation of Natural Scenes. Computer Vision Systems. New York. 1978, pp. 129-163.

9. Horn, B. K. P. "Understanding Image Intensities." Arificial Intelligence 8(1977), $201-231$.

10. Horn, B. K. P. and Sjoberg. R. W. "Calculating the Reflectance Map." Applied Optics 18(1979). 1770-1779.

11. Ikcuchi. K. Shape from Regular Patterns (An Example of Constraint Propagation in Vision). Tech. Rept. A.I. Memo 567. Massachusetts Institute of Technology, March, 1980. Artificial Intelligence Laboratory

12. Ikcuchi, K. and Horn, B. K. P. "Numerical Shapc from Shading and Occluding Boundaries." Artificial Intelligence 17(1981). 141-185.

13. Kanadc. T.. Imerdisciplinany Systems Research Volume 41: Cornpurer Recognition of Human Faces. Birkhauser Verlag. Now York, 1977.

14. Kanadc. T. "Region Scgmentation: Signal vs Scmantics." Cornpurer Graphics and Image Processing 13(1980). 279-297.

15. Kanade, T. "Recovery of the Threc-1)imensional Shape of an Object from a Single View." Arificial Intelligence 17 (1981). 409-460.

16. Kanadc, 'I. and Hcrman. M. Incremental 3D) Mosaic Systcm. Tech. Rcpt. (in preparatron), Carncgic-Mellon Univcrsity Computcr Science [) cpartment, 1982.

17. Kanadc. T. and Kcnder J. R. Mapping Image Propcrties into Shapc Constraints: Skcwcd Symmetry. Affine Transformable Patterns and the Shanc-from-Tecture Paradigm. Tech. Rept. CMU-CS-80-133. Carncgic-Mcllon University Computer Science I) spartment. July, 1980.

18. Kender. J. R. Shape from Texiure. Ph.D. Th., Carnegie-Mellon University Compuicr Science Department, 1980.

19. Iove. D. G. and Binford. T. O. The Interpretation of Three-I Dimensional Structurs from Image Curves. Proc. 7th International Joint Conference on Artificial lntclligence, 1981,pp. 613-624.

20. Mackworth. A. K. "Interpreting Pictures of Polyhedral Scenes." Artificial Intelligence 4 (1973). 121-137.

21. Markowsky, G. Wcslcy, M.^. Fleshing Out Wire Frames. Tech. Rcpt. RC 8124. IBM Rescarch Division. February. 1980. IBM Thomas J. Watson Rcscarch Center, Yorkiown Heights. NY 10598

22. McKcown, D. M. Jr. Maps: Integrating Imagery, Terrain and Map Databases. Proc. IEFE Workshop on Applied Imagery Pattern Rccognition. Scpt., 1982.

23. Minsky. M. L. A Framework for Rcpresenting Knowledge. The Phychology of Computer Vision, New York, 1915,pp. 211-277.

24. Nagao. M., Matsuyama, T. and Ikeda, $Y$. Region Extraction and Shape Analysis of Aerial Photographs. Proc. 4th International Joint Conference on Pattern Rccognition, 1978, pp. 620-628.

25. Nagao. M.. Matsuyama. T. and Ikeda. Y. Structural Analysis of Complex Aerial Photographs. Proc. 6th International Joint Conference on Artificial Intelligence. 1979,pp. 610-616. 
26. Ohta, Y. A Region-Orienied Image-Analysis System by Computer. Ph.D. Th., Kyoto University, March 1980.

27. Ohta. Y.. Kanade. T. and Sakai. T. A Production System for Region Analysis. Proc. 6th International Joint Confcrencc on Artificial Intelligence. Aug, 1979,pp. 684-686.

28. Ohta. Y., Kanade. T. and Sakai, T. "Color Information for Region Segmentation." Compuler Graphics and Image Processing 13 (Scpt. 1980). 222-241

29. Rubin, S. M. "Natural Scene Recognition Using LOCUS Search." Cornpurer Graphicsand Image Processing 13 (1980), 298-333.

30. Shafcr.S. and Kanadc, T. Goniophotomcuy and the Reflectance Atlas. Tech. Rept. (in preparation), CamegieMcllon University, 1982

31. Shafcr. S. and Kanadc. T. Using Shadows in Finding Surface Orientations. Tech. Rept CMU-CS-82-100, Carncgic-Mcllon Univcrsity. Jan., 1982.

32. Shafer,S., Kanadc. T. and Kender. J. Gradient Space Under Orthography and Perspective. Tech. Kept CMU. CS-82-123, Carncgic-Mcllon University, May, 1982

33. Shirai, Y. Recognition of Man-Madc Objects Using Fdge Cuts. Computcr Vision Systems, Scpt, 1978.

34. Wesley, M.A., L.ozano-Pcrez, 'Y., I.cibeman, 1.1.. L.cvin, M.A., Grossman, D.D. "A Gcomctric Modeling Systcm far Automated Mechanical Asscmbly." IBM J. Res Develop. 24. 1 (January 1980).64-74.

35. Wondham, R. J. "Analyzing Images of Curved Surfaces." Artificial Intelligence 17(1981), 117-141. 
